\title{
Sex Work, Motivations for Entry, and the Combined Impact of Both on Mental Health: A Case Report of Japanese Female Patients within Therapeutic Relationships
}

\author{
Masayo Uji \\ Department of Bioethics, Kumamoto University Graduate School of Medical Sciences, Kumamoto, Japan \\ Email: ujimasayo@hotmail.co.jp
}

Received 7 March 2015; accepted 23 April 2015; published 30 April 2015

Copyright @ 2015 by author and Scientific Research Publishing Inc. This work is licensed under the Creative Commons Attribution International License (CC BY). http://creativecommons.org/licenses/by/4.0/

(c) (i) Open Access

\section{Abstract}

The purpose of this study was to explore the motivations for entry into the sex industry. The narratives of four Japanese female psychiatric patients with a past experience of sex work were used for analysis. I identified not only practical factors such as financial difficulties or lack of job skills, but also various psycho-social factors, namely: weak emotional ties with their mothers since infancy, their mothers' tendency to prioritize sons over daughters, unremitting needs for maternal care, fear of rejection and object-seeking behavior, desire to control others, envy and aggressive self-destructive behavior, difficulties in establishing female peer relationships during adolescence, proneness to dependency on male objects through sexual relationships, past histories of crime and delinquency, weak internal motivation, frequent acting out, and addictive behaviors. In this article I discussed whether their mental maladjustment was purely the product of their past experiences as sex workers, or whether in fact both the maladjustment and the motivations for entry were derived from personality characteristics developed since infancy. Although not applicable to every Japanese sex worker, this article presents a preliminary hypothesis regarding the contribution of the above multi-dimensional factors to the motivations for entry, and the following mental maladjustment.

\section{Keywords}

Motivation, Sex Industry, Psycho-Social Factors, Maladjustment, Personality Characteristics 


\section{Introduction}

A considerable number of studies have examined the motivations for entry into the sex industry, which for the purpose of this article includes the hostess trade. Disregarding factors that are highly culturally specific, most studies are in broad agreement regarding the motivations for entering or remaining in the sex trade, including financial motivation [1]-[3]; childhood physical or sexual abuse [1] [2] followed by loss of self-worth [4]; disrupted family life [4]; runaway behavior [2]; homelessness and experience of life on the street [4]; views of prostitution as exciting, glamorous, and empowering [2]; emotional support within a companionship [3]; drug abuse [1]-[3]; desire to gain the attention and acceptance of adults [4]; and self-identity as a professional woman [3]. Some research has referred to the differences between runaway girls and filial daughters [3], and between juvenile and adult prostitutes [2]. But it is also appropriate to consider that motivating factors, their number, and the degree to which each contributes to entry into the sex trade vary from individual to individual. Usually these factors do not contribute singly, but rather interact with each other or form part of a chain reaction [4]. Cusick [4] emphasized that "whatever the power of personal experiences that incline a person towards prostitution, this can still only be possible in specific cultural condition". Studies exploring these motivations within the Japanese cultural context are scarce.

From the viewpoint of clinical psychiatry, examining the entry into the sex trade as well as any subsequent negative experiences is important in terms of understanding the way in which personality pathology contributes to the motivation for sex work and to psychological maladjustment after entry. Previous research has reported a high prevalence of mental disorders among sex workers, such as mood disorder [1] [5], anxiety disorder [5], and PTSD [1] [5]; however, it is not clear whether these disorders cause entry into sex work or are its byproducts. In her literature review, Cusick [4] referred to several articles which viewed engagement in prostitution as a result of various pathologies, such as latent homosexuality, oedipal fixation, low intelligence, emotional disturbance, sex confusion, and poor self-image.

This study did not aim to identify a universal pattern concerning entry into the sex industry and any consequent psychological maladjustment. Rather, as a preliminary work targeting a small number of individuals with past experience as sex workers or hostesses who also had mental disorders, it sought to explore the factors related to motivations for sex work and to psychological maladjustment. More specifically, it examined whether maladjustment was the result of engagement with the sex industry or whether it was instead caused by each individual's dispositional personality characteristics, which also contributed to the motivations for entry.

The approach of most previous studies, some of which are referenced above, was to conduct in-depth interviews with women who used to be or who were still sex workers, focusing mainly on their experience related to sex work. The concern with this approach is that by asking direct questions regarding the women's entry into the sex trade, the interviewer is likely to receive a direct answer (e.g., money) that does not touch on underlying motivations. This problem is further compounded if the interview is only a "one-off." As explained in the previous paragraph, this trial study sought to examine personality characteristics that had been shaped by each subject's interpersonal relationships since infancy, both inside and outside the family. As such, multiple conversations over a significant length of time were desirable. Therefore, this study was based on the stories of four women narrated within therapeutic relationships lasting at least one year, with varying therapy frequencies.

In summary, this report focused on patients with mental disorders who had experience as sex workers. The goals of the study were:

1) to identify the psycho-social factors that influenced entry into sex work, and

2) to determine whether the subjects' maladjustment arose from the above factors or it was primarily the byproduct of sex work.

\section{Methods}

As noted in the introduction, female patients with a past experience of sex work were chosen as the subjects of this study. Their narratives were taken from clinical records between August $1^{\text {st }} 2008$ and August $31^{\text {st }} 2014$. I had treated, or was treating them as the consulting psychiatrist or the psychotherapist in a designated consulting room of one of two hospitals in Japan. I selected four patients from whom I had obtained enough information regarding their life history during consultation or psychotherapy for meaningful analysis. I first identified experiences that seemed to be related to entry into the sex industry or hostess trade, regardless of whether the relations were direct or indirect. Next, I determined the psycho-social factors that seemed to have influenced the 
subjects' maladjustment. Finally, I evaluated whether their mental maladjustment was purely the product of their past experiences as sex workers or hostesses, or whether both the maladjustment and the motivations for entry were derived from personality characteristics developed since infancy. The research protocol was approved by the Ethical Committee of Kumamoto University (Institutional Review Board).

\section{Results}

The outlines of the four patients' life histories, including their course of entry into sex work, are sketched below.

\subsection{Ms. A}

Ms. A visited a psychiatric clinic due to increasing irritability and depressive mood during pregnancy, when she was in her late twenties. In particular, since being pregnant she found herself unable to control her aggressive feelings towards her mother, with whom she had not lived for about a decade. She lived with her husband and her daughter, who was still a baby. She frequently became irritated towards her daughter and in calmer moments worried that her actions might contribute to future mental illness in the child. Ms. A was irritated not only when her daughter showed frustration by crying, but also when she sought greater intimacy. A similar dynamic occurred in her relationship with her dog, namely irritation when the dog desired affection. I provided Ms. A with 30 minutes of psychotherapy once or twice a month. She was diagnosed with hysteroid personality [6] [7] in addition to major depressive disorder.

Ms. A had many of the characteristics typically cited by previous studies as indicative of likely entrance into the sex trade: failure to finish high school, runaway episodes, delinquency, financial difficulties, and lack of job skills. The patient also reported her father's bankruptcy, her parents' marital disharmony followed by divorce, and her subjectively perceived maternal indifference and hatred. Academically, since elementary school she had always ranked in the lowest tier performance-wise. Her relationships with her female friends during childhood were unstable, although marked by less conflict than in later years. She was afraid that she was disliked by them, or that her closest friend would prefer a classmate over her. During the higher grades of elementary school, she once engaged in shoplifting and once stole her friend's stationery, which one of her younger sisters reported to her friend. Even when her teacher directly asked her whether she actually stole her friend's stationary, she never confessed her misconduct. Her mother was consistently indifferent about these episodes, and gave her no instructions or guidance. Ms. A occasionally felt that her mother did not love her. She dropped out of senior high school within the first year because she was not interested in studying. She dated a succession of boys, one of whom was violent toward her. The boyfriend once entered her house through the window of her room at night and began acting violently. Her mother came up to her room and opened the door, but quickly left her room as if she had not seen anything. Immediately following this incident, Ms. A accompanied the man home and stayed with him overnight. She became pregnant with him and subsequently terminated the pregnancy. When informed of the pregnancy, her mother recommended physical exercise to cause a miscarriage. Soon after dropping out of senior high school, Ms. A ran away and moved to a female friend's house. The relationship with this woman quickly soured due to mutual harassment, and they broke contact. This pattern is representative of Ms. A's relationships with other women. When she was 16 years old she started prostitution because she did not have money to pay her mobile phone bills. She had earlier taken part-time jobs in pachinko parlors and restaurants, but was unable to continue these for more than one month. The reasons for these short time frames were not fully verbalized in therapy, but there was a vague mention of a lack of trust in colleagues. Ms. A believed she did not possess the skills for any work other than prostitution. She initially sought clients through classified adverts. Because she perceived her first customer to be very kind, and he did not use force during the encounter, she did not regard the idea of sex with strangers as particularly objectionable. This, coupled with the significant financial rewards, kept her in this line of work. After running away she started working in brothels. During her work as a prostitute she once suffered physical violence, and in a separate incident was almost robbed. She gradually came to abhor being touched by unfamiliar men and quit the job. In total, she continued this job for about five years, but changed brothels several times due to unstable interpersonal relationships. She sometimes took unannounced time off, and on other occasions quit without notice, not responding to her managers' phone calls. She behaved as she pleased. Underlying this impulsive, seemingly irrational behavior was likely an inability to communicate a need for emotional support, which she refused to acknowledge but which had been withheld by her mother since her infant years. After leaving prostitution, she started working as a hostess at a bar where she met her 
current husband. They got married when she was found to be pregnant, although the pregnancy resulted in a miscarriage. After several years she became pregnant again. This time, however, she gave birth to a healthy female daughter. As noted earlier, she found child-rearing overwhelming, which led her to seek early-hour childcare for her daughter before she was a year old. It was difficult for Ms. A to establish mutually reliable companionships with the mothers of other babies, a fact she did not admit to herself. Following her pregnancy she occasionally returned to her mother's house, an expression of the unconscious expectation of maternal care that had always gone unfulfilled due to the mother's indifference. Ms. A was not able to communicate so as to receive her mother's attention. She was not brave enough to show her attachment towards the mother. Overcoming her fear of rejection would have been too difficult. Therefore, all she could do was to hope that her mother would initiate conversation, a hope that remained unrealized. In this situation, instead of feeling emotional pain, she defended against it by devaluing her mother as an incomprehensible person. This pattern reoccurred in her relationship with her female boss, whom she described as a nervous person. She dismissed as of no use the idea of initiating communication with both her mother and boss. Her husband was relatively cooperative. However, she did not feel a sense of reliance on him and did not initiate conversation. At the same time, she felt envy toward him, as she perceived him as having been raised in a favorable family environment. She tried to alleviate her stress by eating chocolate, shopping, and smoking.

She visited my clinic every two or three weeks at the beginning and even now. She occasionally cancels therapy or is late. One of the reasons for this could be because she is not accustomed to keeping promises or being punctual. Furthermore, her verbal ability to describe her emotions and life events is relatively poor due to the lack of communication with her mother since infancy, lack of perceived acceptance by her therapist, and depressive mood. Therefore, of all four women in this study, the information from Ms. A regarding psycho-social factors related to entry into the sex industry and psychological maladjustment is the most limited.

\subsection{Ms. M}

The second patient, Ms. M, visited my clinic in her early twenties due to depressive mood, binge eating, and anxiety. She lived with her parents and grandparents. When I first met her, she could not talk at much length, and instead her mother gave me information on the circumstances behind the symptoms. For this patient, I conducted 30-minute psychotherapy sessions every two weeks. She was diagnosed with hysteroid personality [6] [7] in addition to eating disorder and major depressive disorder.

She had no memory of emotional ties with her mother during infancy or childhood. As in the case of Ms. A, Ms. M's perceived maternal parenting was indifferent and insensitive. When she was in the fourth grade of elementary school, she temporarily became anorexic, likely an expression of unconscious desire to be cared for by her mother. She had an older brother and a younger sister. The mother was basically slow to notice her daughters' poor health and emotional pain, but showed comparatively more affection towards her son. When becoming adults, although Ms. $\mathrm{M}$ and her sister strengthened unity by criticizing their mother behind her back because of her unfair distribution of affection between the son and daughters, the relationship between the sisters was also conflictive over the parents' care.

During elementary school Ms. M was physically assaulted by a male classmate and was touched sexually by a male schoolteacher. Her mother expressed anger with this teacher at home, without ever confronting him, but even as an adult Ms. M had no negative feelings toward him. During junior high school, she was bullied by her female classmates and became isolated from them, but was not able to talk back to the bullies. At some point in the third grade of junior high school, she started going to a cram school to study for the senior high entrance examination. Shortly afterward she stopped attending junior high school. The reason for this unusual decision was that it was too noisy for her to study in the classroom because some students, who had already been admitted to a senior high school based on the recommendation of the junior high school principal, chatted a lot during recess. However, the underlying reason for her dropping out was assumed to be her difficulties in establishing reliable relationships with her classmates. She made her mother drive her to the cram school, reflecting the same attitude she currently adopts in demanding that her mother drive her to the hospital where she receives psychiatric treatment, despite the availability of other measures that would increase her independence. After a short time at the cram school she came to have a romantic relationship with a male teacher, resulting in a competitive relationship with a female friend, and once again isolation from her peer group. Although her academic performance was relatively good, she was not accepted by the senior high school she applied for. She attended another high 
school, where she focused almost exclusively on her appearance in order to avoid being teased by both old and new classmates as well as to rebuild a new self. She occasionally stayed out at night with her boyfriend, and on other occasions shoplifted, both of which elicited parental reprimands.

After graduating from senior high school, she attended a vocational school to become a hairdresser and began living by herself. However, she was not able to cope with the strict atmosphere of the school, and quit within the first year. She then started working at a night club, a fact her parents did not learn of until she developed psychiatric symptoms a few years later. She worked for three years as a club hostess. Her responsibilities were not limited to entertaining male customers, but also involved engaging in false romantic relationships, including dating, outside the club. She said she was happy to tempt male customers. Also, like her colleagues, she enjoyed buying brand-name bags and wearing gorgeous dresses. Some customers annoyed her because they put pressure on her. One tried to initiate sex, but she expressed her rejection by crying and resisting physically. However, she was instructed by the club manager to focus on extracting as much money from them as possible, an order she subsequently followed without question.

It was not the above stressful events in her hostess job, but rather a romantic breakup with her cohabitant, and subsequently living on her own, that brought about depressive feelings, bulimia, and withdrawal from society. She disclosed these feelings to her younger sister, who also used to live alone. Her sister told their mother to take Ms. M to a psychiatric clinic, which resulted in my consultation. After recovering from her most severe depressive symptoms, she attended an appointment with her therapist wearing very revealing clothes and extravagant accessories.

After commencing psychiatric care, she returned to her parents' home to live. At the practical level, her parents were cooperative, for instance driving her to the hospital, purchasing an exercise machine she wanted in order to lose weight, and buying a puppy as she requested. On the other hand, when her parents did not respond in the way she expected, she perceived it as rejection, which led to bulimia and depressive mood. In contrast to her appropriate acknowledgment of her father's support, she tended to deny her mother's routine care, to devalue her, and to characterize her as a person who was slow to notice things, an image of her mother she had held since childhood. Despite the fluctuation of her bulimic and depressive symptoms, they gradually decreased in frequency and severity, and within three years she decided to enter a junior college for training as a child care specialist. Before entering the college she took driving lessons, during which she came to have romantic feelings towards an instructor, and she sought a date with him several times. Eventually the man agreed and she lived with him every weekend. Her therapist at the time interpreted this romantic involvement as a way to gain emotional stability in the face of her inability to focus on her own issues by supporting herself. The pattern seemed to be a repetition of her junior high school period when she had a relationship with the teacher at the cram school.

\subsection{Ms. R}

The third patient, Ms. R, visited my clinic in her mid-thirties with depressive and anxious feelings. The life events before her maladjustment were divorce and bankruptcy caused by her husband's debt. She had signed a guarantee form without asking her husband the meaning of the documents. This blithe acquiescence to others' requests was frequently manifested in her interpersonal relationships. We met for 45-minute psychotherapy sessions once a week. She was diagnosed with "as if personality" [8] in addition to major depressive disorder.

Her life history was somewhat unique in the context of contemporary Japanese society. She began living in a shrine with her grandparents when she was three years old, while her parents continued to live with her twoyear-old brother. The reasons for her separation from her parents were never made clear. Her strong attachment to her grandparents and intense conflict between her grandmother and mother offered a possible explanation, but were not sufficient to rationally explain the separation.

The grandfather used to take her to an Izakaya (a Japanese-style bar). Ms. R said that his care of her after she used the toilet was a good memory. This struck me as strange for two reasons. First, the grandfather used his bare hand instead of paper to wipe her, an act that seemed to contain a sexual element lost on Ms. R. Second, it seemed in this situation that the grandmother would be the most appropriate person to take on the mothering role. However, it became clear later that throughout Ms. R's life, any person, regardless of gender, could be the second mother, the object she wanted to control to fulfill her emotional needs of dependency. This relationship with significant others is consistent with the object relations described by Winnicott [9], who writes that for an 
infant in the early phase of life, their father exists as "another mother.” When Ms. R was four years old, after her grandfather's death, she started living with her grandmother in a love hotel, where the grandmother was working as a live-in staff member. The grandmother was the second wife of the grandfather, so Ms. R was not a blood relative of this woman. In normal circumstances, the death of a child's only blood relative in their home environment would lead to the child being returned to the parents, but that was not the case in this instance. The grandmother started work at midnight, at which time Ms. R was frequently awake. She tried to alleviate her loneliness by holding a doll. This intolerable loneliness was subjectively experienced again and again later in her life, and was the excuse for many of her attitudes and behaviors, regardless of whether they were morally or legally acceptable. In senior high school, Ms. R was shocked to learn that she had in fact lived with her grandmother in a love hotel, and felt strong shame. However, she planned to keep it a secret between her and her grandmother.

She returned to her parents' house with her grandmother when she was six years old. During elementary school, her school performance was excellent. Therefore her elementary school life was relatively easy compared to high school, despite the existence of a strict female teacher whom she prayed would become sick. In the context of her family life, she experienced intense envy toward her younger brother, who had strong emotional ties to their mother and received much maternal praise for his comparatively better school performance. She always felt emotionally distant from her mother. Ms. R even felt that her mother disliked her, and that she would prefer it if her brother were the only child. This relationship was exacerbated by the mother's conflict with the grandmother, to whom Ms. R felt strong attachment. She worked hard in order to surpass her brother in school performance where she could, which she expected to bring about maternal approval and praise. However, no success in this regard was able to bring her a sense of accomplishment. When she occasionally disclosed a variety of somatic symptoms to her mother, she was simply encouraged to go to school. These somatic symptoms seemed to be disclosed in order to elicit maternal care. However, the mother was not empathetic enough to recognize this underlying emotional motivation.

In junior high school, Ms. R was bullied and socially excluded due to her physical appearance, which she blamed on her mother because she did not provide any guidance on personal grooming. This bullying came to an end when a popular boy in Ms. R's class became her friend.

Ms. R's focus in senior high school was to get the attention of classmates by entertaining them. Underlying this behavior was an intense feeling of envy toward a few more popular female classmates. Ms. R sometimes made up stories about herself and even engaged in self-destructive, risky behavior so that her physical appearance would back up her narratives. She strongly disliked losing the attention of others.

Ms. $\mathrm{R}$ had a weak grasp on the concept of personal opinion. For as long as she could remember, she avoided expressing her opinions to others in order to avoid the risk of being disliked due to conflict. However, this behavior pattern produced the opposite results to those she expected, namely, she lost credibility with classmates.

In senior high school, again isolated in her class, Ms. R was comforted by a man who lived in her neighborhood. At the end of her final year of senior high school, her teacher recommended that she attend welfare vocational school because she was the only one in her class who had not decided on her future course. She followed this advice without any careful consideration.

To attend the vocational school, Ms. R had to live separately from her family. This caused unbearable loneliness, so every night she visited her friends or invited them to her apartment. After graduating from the school, she started working at a welfare facility for the elderly. A male coworker who initially visited her at home frequently eventually remained in the house as a cohabitant, an action with which she expressed neither agreement nor disagreement. It should be emphasized here that Ms. R knew when she started living with this man that he was her friend's boyfriend. Although Ms. R expressed neither agreement nor disagreement towards cohabitation, she disclosed to her therapist her envy toward this female friend and was convinced she could make the man choose her instead. Despite her success in winning over her friend's boyfriend, her cohabitation with him was emotionally draining. He frequently went out with his male friends at night, which again brought her intolerable loneliness, and he left the housework to her. She sometimes saw him chatting with female colleagues. For these reasons, she harbored anger towards the boyfriend, jealousy towards her female colleagues, and most of all, the fear that he would forget about her. None of these negative feelings were verbally expressed. Instead, they drove her to actions from which she expected to gain his attention and approval, including going on a diet, visiting hospitals due to the somatic symptoms caused by his absence at night, and changing her hairstyle and fashion. However, it was difficult to gain his attention to a satisfactory degree, and she therefore eventually engaged in 
sexual relationships with other men, some of whom were his friends. These sexual relationships alleviated her nighttime loneliness. She expected that he would be told of her sexual relationships with other men and believed that this would result in both his jealousy towards the men and an increase in his attention and love towards her.

At some point in the fifth year of their cohabitation, they broke up when the man began dating another woman. Ms. R.'s female colleagues tried to comfort and cheer her up, but she told me that in fact they looked down on her as someone who had been miserably abandoned. Before the breakup she had harbored feelings of superiority toward female colleagues who did not have a boyfriend, and she believed that these colleagues were now enjoying proving her wrong. Despite these negative feelings toward her colleagues, she accepted their attention because she was unable to be alone. She also called on her mother, broke down over the impossibility of giving up her boyfriend, and revealed plans to win him back. However, her mother told her that her planned actions were completely undignified. This admonition disappointed her expectation that her mother would manage Ms. R's difficulties by any means. Following this, Ms. R began to desperately tempt many men in whom she had no genuine interest. Every weekend, she returned to her parents' home with a different man. Behind this behavior was the message to her mother that Ms. $\mathrm{R}$ was comparatively more valuable because she could attract many men. If any of these men fell in love with Ms. R, she abruptly rejected them by avoiding them. She believed that she could control any man by having a sexual relationship with him. Her promiscuity came to be known in her neighborhood. She then married a man who treated her very kindly while they dated. He pushed for the marriage; again, she expressed neither agreement nor disagreement.

Several years into the marriage she could no longer deny that her husband carried a huge debt. Now in her early thirties, to help repay this debt she started working as a club hostess at his request. Despite her anger toward her husband, she obeyed his request because her husband also worked at night and her new work therefore alleviated her loneliness. When she was working at the club, she met a male customer known only as the "president," who invited her to become a prostitute. She did just as the "president” required, including dealing with violent customers and having a sexual relationship with the "president" in return for his favor and a privileged position above the other prostitutes. In addition to prostitution, she became addicted to shoplifting and illegal drugs. Lack of sleep led to frequent traffic accidents, for which she did not feel any responsibility; she asked an insurance company representative for help in avoiding having to pay compensation. Furthermore, she was unable to concentrate on her daytime job due to sleepiness, and had an affair with a male colleague who had a wife and children. These issues at her workplace caused her colleagues to develop negative feelings toward her. When she perceived their anger and rejection, she quickly quit the job. She even adopted self-destructive behavior, for instance ingesting a detergent when she felt unable to tolerate the difficulties in her interpersonal relationships. Her income increased, but she hardly spent any money on food and gradually lost weight. Every morning when she returned home, she left her night's earnings on a table in the living room for her husband. Her husband, having been told by a friend that she was working as a prostitute, thought she must be mentally ill and recommended she be hospitalized. She offered to divorce, a means of expressing her rejection of him. In her mind, the only reason she entered the sex industry was external, namely her husband's request that she work at night for money. Similarly, she attributed her anorexia to not having enough money to eat because her husband needed it to pay back his debt. However, this was inconsistent with a fact that emerged in a later therapy session, that she sometimes stole money from the husband's wallet.

Ms. R did divorce her husband, after which she returned to her parents' house and began visiting my clinic. Within a few months after returning to her parents' house, she became bulimic due to anxiety and fear she experienced at night while her parents were asleep, resulting in a $30 \mathrm{~kg}$ weight gain. She eventually started working at a welfare facility near the house. As occurred during senior high school and in her twenties, she harbored envy toward a woman who seemed to be blessed with a fortunate home life and who had gained popularity, in particular with male colleagues. Also, her stereotypic interpersonal behaviors always manifested in all relationships in which she detected even a hint of warmth, whether with colleagues or others. She experienced disappointment at failed attempts to elicit praise, care, support, or approval by meeting assumed expectations, expressing false empathy, and giving small gifts. Once, she was made fun of by her female colleagues, probably because she had always tried to give the image of being a model professional. Her colleagues' behaviors caused strong feelings of rejection and resentment. In the past, this type of situation would cause her to quickly enter into sexual relationships with men, but this time she tried to escape from her painful experiences in the real world by watching a movie whose protagonist was a prostitute. However, against her expectations, the prostitute in the story was killed by her mother. 
Ms. R's relationship with her mother was the archetype for all others, including those described above. As in childhood, she continued to tell her mother about her somatic symptoms, but this never resulted in expressions of care. Furthermore, she occasionally made her parents drive her to the hospital, which she justified by her bad physical condition. Currently, she gives money to fund her mother's gambling addiction, but her mother's gratitude usually does not last longer than a few seconds. In therapy sessions she has expressed sadness and loneliness, as well as anger and denigration towards the mother. She even told me that she envied her mother, as "she seems to live with fewer constraints.” When at a family party she thought she succeeded through various means at socially isolating her mother from the party attendees, her aggression was satisfied and she reported the incident to me with pleasure.

\subsection{Ms. S}

The fourth patient, Ms. S, was in her early twenties when she first visited me. She perceived as having been tortured by negative interpersonal life events with almost all people with whom she was currently or had previously been in contact, resulting in intense resentment followed by repeated self-destructive acting out, i.e. overdosing and bulimia. She also had many experiences of abandonment. I met with her for 45 minutes of psychotherapy every week. She was diagnosed with borderline personality disorder. During the treatment, she asked me to prescribe many minor tranquilizers, an expectation I could not fulfill.

She lived with her parents and one of two older brothers. This brother was schizophrenic and both parents had to devote themselves to taking care of him, which Ms. S resented. Throughout her life history, she perceived that she was regarded by her parents as less important than her brothers. Ms. S had been sexually exploited repeatedly by an elder brother during her elementary school years. Ms. S felt that she was not allowed to disclose this to others, including her mother, and thought her home life forbade her from romantic involvement outside the household. But she came to have romantic feelings toward boys at school, which resulted in uncomfortable feelings of conflict. After entering her twenties, she told her mother about the past negative sexual experiences with her brother. Behind this disclosure was her envy and aggression towards the elder brother, although these feelings were actually more intense towards his wife. For Ms. S, his happy marriage was impossible to accept, without his consideration of and regret over his past misconduct. Before the brother's marriage, Ms. S's perception of him had not been necessarily negative, rather, she liked him, but after his marriage she was possessed by the idea that the wife was the only women her brother loved, and she was used just as a tool for his sexual desire. She experienced these feelings of aggression and envy not only toward this woman, but toward any who seemed to be happy, including her mother: "My mother was able to get married, but I am not."

As with the three women already discussed, Ms. S could not recall expressing her emotional needs to her mother until pre-adolescence, though since adolescence this has not been the case. At school as a preadolescent, a relationship with a male schoolteacher was very discordant. In addition, Ms. S had difficulties establishing stable relationships with her classmates. She always felt that she was treated badly and insulted by classmates as well as other schoolmates. When she was in the fifth grade of elementary school, her father told her to check on her mother, who was participating in a community meeting that night, because he was afraid that the mother was engaged in an affair. Ms. S currently feels anger toward her father regarding this event because he did not care about her security but was instead focused solely on her mother, toward whom she felt strong envy.

Immediately before graduating from senior high school, Ms. S started having sexual relationships with anonymous men who picked her up on the roadside, and later learned she could earn money by having sex. Her motivations behind this were to show her father that she was able to earn money and have sex with many men. She said that her father occasionally boasted of his numerous past sexual relationships, and when she asked him to buy something he looked down on the fact that she was unable to earn money.

Thus the initial reasons for these behaviors were defiance towards her father, and later, desire for money. However, once she started prostitution, Ms. S's initial needs were further complicated by emotional dependence, i.e. to be cared for by the males in these sexual relationships. From these men's perspective, she was something to be bought. Inevitably, her fears of abandonment were realized repeatedly.

At one point she became pregnant due to a sexual relationship with a married man. Her age and economic status meant that abortion was her only viable option. The man refused to pay for the procedure and when pressed, threatened to expose Ms. S's prostitution to her mother. Ms. S expressed her resentment toward the man to her mother, who remonstrated with him, unsuccessfully, under the impression that the baby had been con- 
ceived conventionally outside a worker-client relationship.

Continuing her independent work, Ms. S also started a job as a prostitute in an adult entertainment establishment. When she was initially approached by a man recruiting for the business, her reaction was one of fear. But when the man began to back off, her fear of abandonment was stimulated and she agreed to take the job. Her income was approximately ten thousand dollars per month, almost all of which was spent on hairstyle and lavish dresses. At some point, her mother intuited her line of work and scolded her. However, Ms. S ignored her.

Because she was always sensitive to the words of others, she again started to perceive disapproval, rejection, and disrespect in both staff and customers, and she frequently voiced her displeasure. One of the customers once told her she was "crazy." Her maladjustment necessitated frequent workplace changes, with her longest stay in any one establishment being merely three months. However, she was not able to quit prostitution because she did not have any skills she felt confident she could use for other work.

Eventually, however, she was sexually and financially exploited by her manager, and rumors of violence and enforced drug consumption in the work place led her to quit out of fear. She also stopped her work as an independent prostitute. After quitting prostitution, she impulsively entered a few sexual relationships with unrealistic expectations her partners could not fulfill. After having consensual sex a number of times, she expressed rage at having been, in her view, used.

Once she turned twenty years old, she disclosed to her mother her traumatic childhood sexual experience with her brother. Her mother responded: "it cannot be helped, because it has already happened." This seemed to be a microcosm of Ms. S's relationship with her mother: her expectations always being betrayed by her mother's unempathetic attitudes towards her. Her father's response was even worse, as he believed that she must have made up the story. These reactions re-traumatized her 10 years after the initial events.

After repeated breakups with men, she was eager to have peer relationships with women, which had not been possible during her adolescence. However, once these relationships began, she experienced unbearable envy, feelings of rejection, and aggression toward the women. For example, at the vocational rehabilitation center she started attending after launching psychotherapy, she felt envy toward women who had graduated from university or who were popular with male members. Therefore, it was difficult for her to have long-lasting reliable relationships with women. In various social milieus, she was often excluded from women's company. Her unfulfilled needs were transformed into aggression, which her mother was not able to empathize with, which further drove her to abandonment fear and the action of testing and evaluating her mother: for instance, how hermother advised her on difficulties, whether her mother responded to her requests such as to be driven to the hospital, whether her mother gave her pocket money, whether her mother believed her side of any story, and so on. Ms. S frequently became disappointed in her interactions with her mother and would stay in her room with the cat or became angry and shouted at her mother.

\section{Discussion}

\subsection{Factors That Were Common to More Than One Patient}

Here, I would like to outline the common factors identified in at least two of the four women.

1) Weak emotional ties with their mothers since infancy

Without exception, the maternal attachment of each woman was weak during the period of infancy and elementary school. Their mothers were comparatively indifferent, insensitive, and inconsiderate towards them, rather than abusive, authoritarian, and didactic.

2) Unremitting need for maternal care, fear of rejection, and object-seeking behaviors

Even after becoming adults, Ms. M, Ms. R., and Ms. S still had an intense expectation to be cared for by their mothers. They attempted to obtain maternal care through appeals for practical assistance, such as requests for hospital lifts or money. Ms. R tried to gain her mother's affection by fueling her mother's addiction. In the case of Ms. A, the emotional needs were suppressed and latent. These women's need to be cared for was not limited to their mothers, but extended to many people, especially male objects whose rejection they always feared.

3) Desire to control others

Ms. R tried to control others through disclosing somatic symptoms, expressing false empathy, and pandering. In the case of Ms. M, symptoms of an eating disorder could be viewed as a strategy for controlling others. Ms. R and Ms. S tried to manipulate others through self-destructive behaviors. All women except Ms. A made their parents drive them to the hospital, although they themselves were able to drive. 
4) Envy and aggressive self-destructive behaviors

All patients except Ms. M expressed feelings of envy toward their mothers, female friends, relatives, spouses, and siblings. Ms. A confided in me her envy toward her husband. Furthermore, she expressed occasional hatred toward her baby and dog, specifically with regard to their dependence on her, as they freely sought her affection in a manner that had never been possible for her. In the case of Ms. M, due to narcissistic pride, she seemed to deny her envious feeling towards her siblings in relation to her mother's unfair distribution of affection. Rather than recognizing her own envy, she devalued her mother. Aggressive self-destructive behaviors as retaliation were prominent in the cases of Ms. R and Ms. S. Both disclosed intense feelings of envy towards women who seemed to be happy and who had succeeded in gaining a male's attention or having a stable partner, including, in the case of Ms. S, her mother. Ms. S not only harbored envy toward her mother but also competitive feelings toward her father, who boasted of his sexual experiences, and these feelings drove her to engage in anonymous sexual relationships.

5) Mothers prioritizing sons over daughters

Of the four women, all three who had male siblings believed that their mothers experienced and exhibited more affection for their male siblings than for them. Ms. R further felt that she was an unwanted child and that her mother was fully emotionally satisfied by her son.

6) Difficulties in establishing female peer relationships during adolescence and proneness to dependency on male objects through sexual relationships

Without exception, all four women were unable to establish trustful relationships with female friends and were inclined to sexual relationships with the opposite gender. This pattern formulated in adolescence continued to the present time.

7) Past histories of crime and delinquency

Histories of shoplifting were reported by three patients-Ms. A in childhood, Ms. M in late adolescence, and Ms. R in her early thirties. Furthermore, Ms. R used to be addicted to an illegal drug.

8) Weak internal motivation

Refusal to attend school and dropping out were reported by Ms. A, Ms. M, and Ms. S. Even acknowledging the strict school atmosphere, these women's internal motivation [10] to perform well academically seemed to be comparatively weak. This weak motivation was also seen in their inability to keep a job, and in Ms. A's failure to attend therapy with regularity. In particular, Ms. R's motivation for school and job performance was always external, in that she tried to elicit attention and praise from her mother and other people. The egos of these women were always at risk of intense internal aggressive impulses when their expectations of others went unrealized.

9) Longing for beautiful external appearance

This was identified in the cases of Ms. M and Ms. S, and was caused at least in part by their competitive feelings with other women as well as their attempts to reassert their value.

10) Frequent acting out

Most of the women did not seem to carefully consider their difficulties before making decisions. Rather, they resolved their conflictive situations by acting out, for instance by running away, quitting their jobs, having sexual relationships, binge eating, and overdosing.

11) Addictive behaviors

These occurred in every woman if we regarded binge eating as an addictive behavior. The objects of addiction were varied, including food, consumer goods, illegal drugs, and minor tranquilizers. Ms. R's compulsive devotion in the context of interpersonal relationships, and her shoplifting (also conducted by two other women), can also be seen as addictive behaviors. In addition to this, Ms. R and Ms. S were addicted to sexual relationships with anonymous men.

12) Past negative sexual experiences

Ms. M was sexually abused by a schoolteacher, although she did not necessarily view this as negative. Ms. S's sexual exploitation by a family member was defined as “negative” only after the perpetrator's marriage.

13) Lack of job skills coupled with financial difficulties

Ms. A believed that she lacked any job skills other than those of a sex worker. At first appearance, Ms. R became a prostitute to repay her husband's debt, but other factors, such as intolerable loneliness at night and desire for her husband's praise as well as protest against him, make for more convincing reasons. In her case, the feeling of omnipotence gained by controlling men through sexual relationships was a prominent factor. Ms. S tried 
to earn a significant amount of money to prove to her father that she could do so, which meant that her motivation regarding income was more psychological than financial. This could be applicable for every woman except Ms. A, in whom purely financial motivations were not improbable.

14) Intra-familial disharmony

Ms. A reported clear marital disharmony between her parents. Ms. R identified conflict between her mother and mother-figure (grandmother).

\subsection{Interpretations}

Based on the numerous factors identified in the clinical materials above, I would like to present a broad hypothesis regarding the motivations underlying entry into the sex industry and hostess trade. The most prominent factors were these women's weak maternal bonds since infancy, and their intense emotional needs toward significant others, including their mothers. The lack of "experience of omnipotence" [11] within the mother-infant relationship led to Ms. R and Ms. S’s inability to give up their omnipotent expectations of significant others. Ms. $\mathrm{R}$ always tried to guess others' motivations and wants, desperate to fulfill them and thus gain favors through pseudo-empathetic attitudes and object-satisfying behaviors. These would then convince her that she could control others in the way she desired. When this conviction was betrayed, she immediately turned to acting out by way of promiscuity, self-destructive behavior, or negligence of her job duties. Ms. S's expectations of emotional care were too intense to be realized, resulting in aggressive acting out following feelings of rejection. Ms. A was not able to initiate conversation due to fear of rejection, leading to interpersonal relationships that seemed to replicate that with her mother. These women's inability to express their emotional needs straightforwardly led them to try to temporarily fulfill their needs by coercing practical assistance. Ms. M's anorexia during elementary school could be regarded as an unconscious intention to both test and evaluate her mother through challenging behaviors [12].

In addition to the lack of maternal care within the dyadic relationship with the mother, in the context of triadic family relationships three women perceived they were being neglected by their mothers in comparison with their male siblings. Ms. A was the exception because she did not have a male sibling. Insufficient maternal care and support, as observed in Ms. A and Ms. M, also played a crucial role in the development of conflict with a female sibling. These women's weak emotional ties with their mothers resulted in their failure to incorporate the "egosupporting mother" [13] and acquire the "capacity to be alone” [13], which in turn caused intense object-seeking tendencies. These women ended up feeling disappointed and rejected by their chosen object of the moment due to this individual's failure to fulfill their emotional needs, and this usually resulted in feelings of aggression toward the objects. This aggression was not initially experienced with the chosen objects, instead having its origin in the archetypical relationship with the mother, toward whom the women felt intense feelings of envy. This envy was re-experienced with various chosen objects: Ms. S had an intense envy of her parents' sexual relationship, Ms. R was envious of her female friends and colleagues, and Ms. A experienced envy of her husband. These frequently aroused feelings of envy could be attributed to a basic lack of satisfaction in the maternal care received. Although Ms. M did not clearly express her envy, this was not necessarily an indication of its absence.

The above factors made it difficult for these women to experience a psychologically healthy adolescence. Blos [14] defined adolescence as the "second individuation process". In this process, an adolescent's ego struggles to repress the incestuous fantasies that increase with genital impulses caused by physical sexual maturation [15], and adolescents disengage themselves from infantile objects (parents) [14]. Keeping distance from their parents and family members usually causes the adolescent's ego to become unstable, resulting in new attachments to various love objects outside of the family whom the adolescents choose as substitutes for their abandoned parents. Despite the passionate and exclusive nature of the attachment on each occasion, each relationship is very fickle and is easily replaced by the next object, which should be distinguished from the adult's stable interpersonal relationships [15]. However, these transient relationships are crucial in order for the adolescent to attain psychological balance. Blos [16] writes that the object choice of early adolescence is the adolescent's friend. The choice is based on the narcissistic nature, as the adolescent chooses and loves anyone without whom they cannot achieve their ideal self-image, which contributes to their narcissistic balance. Despite the girl's bisexual object choice during early adolescence compared to the boy's homosexual object choice, the lack of female friends causes emotional crisis for girls, such as despair, depression, and loss of interest [16]. As Japan has become more westernized, communities have become less close-knit, which has driven some individuals to feel 
isolated [17]. The "circle-based self" is used to alleviate this feeling of isolation through temporary peer circles, usually of the same gender, and has its roots deep in adolescent mentality. Nishizono [17] hypothesizes that in contemporary society, it also functions as a mental support for young adult men, regardless of whether the members' motivations for organizing the circle is constructive or pathological. He added that the need for the "circle-based self" is more intense among women than men, and failure to belong to such a circle results in mental maladjustment. The four women analyzed in this article were not able to benefit from the mental support of a circle due to fear of rejection, envy, and desire to obtain others' attention and approval, all of which arose from a lack of self-esteem.

Addictive behaviors, including binge eating and shoplifting, can be regarded as ways of latching onto a transitional object [18], primarily because these individuals have not incorporated the "ego-supporting mother" [13], and secondarily because they have not been able to establish a mutually reliable relationship with a new significant other due to un-relinquished omnipotent expectations and lack of empathy. Ms. R's anorexia could be considered an expression of aggression towards her husband, who had failed to provide her with care and attention, by provocatively attacking her own body.

These women's casual sexual relationships can be understood in terms of their trying to alleviate feelings of isolation and thereby recover self-esteem. Allowing others to exploit their sexuality seemed to be the quickest way to get these individuals' attention, despite the false nature of this activity. Blos [16] writes that females' delinquent sexual behavior is based on pseudo-sexuality: a manifestation of their defense against the strong regressive pull to the pre-oedipal mother. He also writes that this sexual behavior is a form of revenge against their mother, who they feel rejected them, by showing that they have somebody, an interpretation which could be applicable to Ms. R. For each of the four women in this study, gorgeous dresses were the strategy through which to assert her superior value, primary to her mother, but also to other women. Other anti-social behaviors such as shoplifting could be regarded as a way of gaining their mothers' attention. When they broke down immediately after failed relationships with men, they regressed to depending on their mothers by manipulating them.

Another shared feature among the four women was the lack of sound ego-function, due to failure to incorporate the mother's ego function. Their tolerance for frustration was extremely low, and they tended to lack the ability to find solutions to problems, resulting in refusal to attend or dropping out of school. Ms. R's relatively favorable school performance was motivated by the desire for her mother's praise. Her motivation was always external: her object's transient attitudes toward her determined whether she devoted herself to a job or abandoned it. In the cases of Ms. A and Ms. S, low ego-function resulted in the failure to acquire job skills, and the sex industry seemed to be the easiest way to fulfill emotional and material needs. In addition to the incorporation of the mother's ego function during infancy, Blos [16] discusses the importance of the latency period, when a child becomes able to use a variety of ego activities, "sublimatory, adaptive and defensive in nature", developed through identification with parents. These then bring about the child's "sense of self-esteem derived from achievement and mastery" and "inner resourcefulness". Freud [15] writes that in the latent period, complete dependency on parents during infancy is usually replaced by the introjection of objects, including parents and teachers, which strengthen the child's ego function, giving them a sense of self-esteem. It might be assumed that in the cases of the four women discussed in this article, lack of experience being dependent on their parents during infancy made it difficult to obtain stable and flexible ego-function during the subsequent latency period. They were thus lacking in internal motivation derived from ego-function.

Negative sexual experiences during childhood were reported by two women. Neither of these necessarily perceived the perpetrators negatively at the time, and instead viewed them positively. The weak emotional ties with their mothers appeared to have made them value attention from anyone as emotional comfort. It was probable that these past sexual experiences opened their eyes to the possibility of obtaining attention through sexual contact, which formed a basis for their later entry into the sex industry when they had maladaptive interpersonal relationships.

From here, I would like to discuss the disparities between previous research and my own observations. Past studies have reported that a significant number of prostitutes at some point experience homelessness or street life. However, this was not the case for any of the four women discussed in this article. This might be due to the culture in which they live. In Japan, young people are more dependent on their parents, even in conflictive relationships, which would deter them from runaway behavior and protect them from homelessness and street life. Furthermore, as seen in the case of Ms. A, young people who run away due to conflict with their parents can usually find a friend who will take them in, even if their relationship is not a strong one. 
In this research, the primary factors that seemed to have mobilized these women to enter the sex industry or hostess trade were related to their personality pathologies. This might be due to the fact that the four women were clinical patients. If non-clinical women had been evaluated instead, more practical factors such as financial difficulties, low academic performance, lack of job skills, and experience with homelessness may have been identified. One additional difference between the current study and previous articles was that among the four women, none was proud of being a sex worker.

Finally, the second research question of this study should be discussed. In my view, these women's current maladjustment cannot be viewed purely as a byproduct of their experience as sex workers. Rather, entering as well as leaving the sex industry can be seen as stages leading to later maladjustment. Retrospectively viewing their life histories, the primary indicator of later maladjustment appeared to be the lack of stable and warm emotional ties with their mothers in early life. This factor interacted in complicated ways with many other factors, such as sexual trauma, difficulties in cultivating ego function, family dynamics, and failure to complete the "second individuation process" [14] through peer relationship during adolescence. As Blos [16] noted, "in female delinquents the infantile instinctual organization breaks through with the onset of puberty and finds a bodily outlet in genital activity". He defined this as pseudo-sexuality, behind which wass "an unduly deep and lasting attachment to the pre-oedipal mother [16]". He adds that the motivation of young prostitutes is due to their emotional constellation. In my view, this statement cannot be generalized to all sex workers. However, inferring from the four women described above, the motivation for entry into the sex industry or hostess trade is strongly influenced by the pre-oedipal mother, at least in clinical populations.

\subsection{Limitations}

First, the four women analyzed in this article was not homogenous in terms of age of entry into the sex industry, type of sex industry or hostess trade, social status, or educational background. It is plausible that if we analyze a homogenous group, more common factors will be obtained.

Second, it is probable that I obtain a limited range of information useful for this study because my purpose of interviewing these patients is to treat their mental disorders. However, I believe that in many ways, evaluating countless narratives during psychotherapy in the context of a deep therapeutic relationship can be more valuable than a small number of interviews tailored to investigate a particular research topic. It might be difficult for some patients to disclose their past experiences due to fear of rejection by the therapist. However, this could also be the case outside of therapeutic relationships, including in the context of research interviews.

\subsection{Conclusion}

Through analysis of limited clinical materials, this study reached the conclusion that entry into the sex industry was intrinsically related to each patient's entire emotional constellation, although in some cases material or practical factors were involved to a minor degree. For certain women, working in the sex industry can be regarded as an attempt to compensate for unmet emotional needs of dependency at the cost of their own sexuality. Entry into the sex industry resulted in additional traumatic experiences because for men these women were simply sexual targets, not the objects of love. In the author's view, the sex industry exploited the vulnerabilities of these women's personalities.

\section{Acknowledgements}

The author would like to express deep gratitude to the four patients, as well as to Emeritus Professor of Fukuoka University, Masahisa Nishizono, who supervised her in treating these patients.

\section{Conflict of Interest}

There is no conflict of interest to declare.

\section{References}

[1] Chudakov, B., Ilan, K., Belmaker, R.H. and Cwikel, J. (2002) The Motivation and Mental Health of Sex Workers. Journal of Sex and Marital Therapy, 28, 305-315. http://dx.doi.org/10.1080/00926230290001439

[2] Cobbina, J.E. and Oselin, S.S. (2011) It's Not Only for the Money: An Analysis of Adolescent versus Adult Entry into 
Street Prostitution. Sociological Inquiry, 81, 310-332. http://dx.doi.org/10.1111/j.1475-682X.2011.00375.x

[3] Hwang, S.L. and Bedford, O. (2004) Juveniles’ Motivations for Remaining in Prostitution. Psychology of Women Quarterly, 28, 136-146. http://dx.doi.org/10.1111/j.1471-6402.2004.00130.x

[4] Cusick, L. (2002) Youth Prostitution: A Literature Review. Child Abuse Review, 11, 230-251. http://dx.doi.org/10.1002/car.743

[5] Rössler, W., Koch, U., Lauber, C., Hass, A-K., Altwegg, M., Ajdacic-Gross, V. and Landolt, K. (2010) The Mental Health of Female Sex Workers. Acta Psychiatrica Scandinavica, 122, 143-152. http://dx.doi.org/10.1111/j.1600-0447.2009.01533.x

[6] Easser, B.R. and Lesser, S.R. (1965) Hysterical Personality: A Re-Evaluation. The Psychoanalytic Quarterly, 34, $390-405$.

[7] Zetzel, E.R. (1968) The So-Called Good Hysterics. The International Journal of Psychoanalysis, 49, 256-260.

[8] Deutsch, H. (1942) Some Forms of Emotional Disturbance and Their Relationship to Schizophrenia. The Psychiatric Quarterly, 11, 301-432.

[9] Winnicott, D.W. (1960) Ego Distortion in Terms of True and False Self. In: Winnicott, D.W., Ed., The Maturational Processes and the Facilitating Environment: Studies in the Theory of Emotional Development, Karnac Books, London, 140-152.

[10] Ryan, R.M. and Deci, E.L. (2000) Self-Determination Theory and the Facilitation of Intrinsic Motivation, Social Development, and Well-Being. American Psychologist, 55, 68-78. http://dx.doi.org/10.1037/0003-066X.55.1.68

[11] Winnicott, D.W. (1962) Ego Integration and Child Development. In: Winnicott, D.W., Ed., The Maturational Processes and the Facilitating Environment: Studies in the Theory of Emotional Development, Karnac Books, London, 56-63.

[12] Nishizono, M. and Yasuoka, H. (1979) Wrist Cutting Syndrome. Japanese Journal of Clinical Psychiatry, 8, 13091315.

[13] Winnicott, D.W. (1958) The Capacity to Be Alone. In: Winnicott, D.W., Ed., The Maturational Processes and the Facilitating Environment: Studies in the Theory of Emotional Development, Karnac Books, London, 29-36.

[14] Blos, P. (1967) The Second Individuation Process of Adolescence. Psychoanalytic Study of Child, 22, 162-186.

[15] Freud, A. (1966) Defense Motivated by Fear of the Strength of the Instincts Illustrated by the Phenomena of Puberty. The Ego and the Mechanisms of Defense (Revised Edition). Karnac Books, London, 137-172.

[16] Blos, P. (1962) On Adolescence: A Psychoanalytic Interpretation. The Free Press, a Division of Macmillan Inc, New York.

[17] Nishizono, M. (1999) Pathology of Circle-Based Self and Psychotherapy. Japanese Journal of Psychotherapy, 25, 444447 (in Japanese).

[18] Winnicott, D.W. (1953) Transitional Object and Transitional Phenomena. International Journal of Psychoanalysis, 34, 89-97. 